\title{
Effect of Semiconductive Layer on Space Charge Accumulation in XLPE
}

\author{
Bai Huan*, Guangmao Li, Gang Du, Jun Xiong and Wenxiong Mo \\ Electric Power Research Institute, Guangzhou Power Supply Bureau, Guangzhou, China
}

\begin{abstract}
Long time DC pressure on high voltage cables will lead to the accumulation of space charge in XLPE cables, thus endangering cable insulation. In order to study the effect of the thickness of semiconducting layer on the space charge in XLPE, the space charge in $10 \mathrm{kV}$ and $220 \mathrm{kV}$ XLPE sample with different thickness of semiconducting layer was measured and compared based on PEA method. Firstly, the samples were pressurized to the specified voltage, then kept this voltage for 30 minutes, then depressurized to 0 , and lastly maintained for 90 minutes. The variation of space charge distribution during the pressurized stage was analyzed with the space charge density as the characteristic parameter. The results show that the space charge near the anode and cathode is accumulated by the semi-conductive coating during the period of maintaining pressure; the thicker the semi-conductive layer is, the more obvious the accumulation of space charge is; the longer the time of maintaining pressure, the more space charge accumulates.
\end{abstract}

Keywords: Space charge; Crosslinked polyethylene; Semiconductive layer; Electroacoustic pulse method.

\section{Introduction}

XLPE cables are widely used in power systems of various voltage levels because of their excellent electrical performance, simple structure, convenient laying and high reliability of power supply. However, the insulation structure of the cable will be damaged due to the bad technology in the process of cable processing and laying or the external damage during operation, and partial discharge will occur when the cable is subjected to voltage [1-3]. Long-term partial discharge will lead to insulation aging and deterioration until breakdown, resulting in serious accidents. Partial discharge detection of cables can effectively detect insulation defects of cables and eliminate hidden troubles in time. It is of great significance to ensure the safe operation of cable lines and even the whole power system.

In partial discharge detection, oscillation wave is widely used in cables with $35 \mathrm{kV}$ and below voltage level because of its excellent performance, but it is seldom used in cables with $110 \mathrm{kV}$ and above. One of the reasons is that people worry about the accumulation of space charge caused by DC pressurization process, which endangers cable insulation. In order to study the effect of semiconducting layer thickness on space charge in XLPE, it is

* Corresponding author:15288080@qq.com 
necessary to prepare samples and measure space charge density in XLPE by electroacoustic pulse method.

Electroacoustic pulse (PEA) method is an effective method for measuring space charge of solid insulating materials. In recent years, scholars at home and abroad have used this method to study the space charge characteristics of XLPE insulating materials. Based on PEA method, there are a wide range of studies, mainly involving: 1)the influence of field strength, frequency, temperature, cross-linking by-products and other factors on space charge accumulation of XLPE materials; 2)the relationship between space charge distribution and insulation aging. Based on the key issues in the above research fields, many scholars at home and abroad have carried out a lot of experiments and conducted indepth research. Liu Jun and others in China have studied the space charge distribution characteristics of cables at different core temperatures [4-5], Zhong Qiongxia and others have studied the relationship between space charge characteristics and cross-linking byproducts under DC high voltage [6], Chen Zhengzheng and others have studied the relationship between space charge characteristics and electrical aging degree [7-8]. The phase characteristics of space charge distribution under AC inhomogeneous electric field were studied by Muratak et al. abroad[9]. Roy S L et al. studied the effect of polarizable impurities on space charge electric field distribution in cable polymers[10]. Tanaka $\mathrm{T}$ studied the space charge properties of XLPE/SiO2 nanocomposites [11]. YingLi et al. studied water content. Space charge distribution of branch XLPE cable under AC electric field [12].

Therefore, $10 \mathrm{kV}$ and $220 \mathrm{kV}$ XLPE samples with different thickness of semiconductive coatings were prepared in this paper. The change of space charge accumulation in XLPE during 30 minutes of maintaining pressure was studied by rapidly increasing voltage to $30 \mathrm{kV} / \mathrm{mm}$, maintaining pressure for 30 minutes, rapidly lowering pressure to 0 and maintaining 90 minutes. The effects of different thickness of semi-conductive layer on space charge accumulation of $10 \mathrm{kV}$ and $220 \mathrm{kV}$ XLPE samples were investigated.

\section{Testing Samples an Testing System}

\subsection{Sample preparation}

The selected samples are $10 \mathrm{kV}$ and $220 \mathrm{kV}$ XLPE with sizes of $60 \mathrm{~mm}$ x $60 \mathrm{~mm}$. he semiconductive layer on XLPE is prepared by spraying two and three layers of semi-conductive paint. The XLPE samples before and after spraying are shown in Fig. 1. XLPE specimens sprayed with semi-conductive paint were observed and measured under a microscope. The thickness of two voltage grade specimens was obtained as shown in Table 1. Figure 2 shows the measurement process of the sample.

Table 1. Thickness of $10 \mathrm{kV}$ and 220kV XLPE specimens with different coating

\begin{tabular}{|c|c|c|c|c|}
\hline sample & $\begin{array}{c}\text { Thickness of } \\
\text { XLPE(mm) }\end{array}$ & $\begin{array}{c}\text { Thickness of } \\
\text { Semiconductive } \\
\text { Layer(mm) }\end{array}$ & $\begin{array}{c}\text { Total } \\
\text { thickness(mm) }\end{array}$ & Voltage(kV) \\
\hline 10 kV uncoated & 0.33 & $/$ & 0.33 & 9.9 \\
\hline 10kV Two-Layer Coating & 0.36 & 0.02 & 0.38 & 11.4 \\
\hline 10kV Three-Layer Coating & 0.36 & 0.03 & 0.39 & 11.7 \\
\hline 220 kV uncoated & 0.37 & $/$ & 0.37 & 11.1 \\
\hline 220kV Two-Layer Coating & 0.35 & 0.02 & 0.37 & 11.1 \\
\hline $\begin{array}{c}\text { 220kV Three-Layer } \\
\text { Coating }\end{array}$ & 0.38 & 0.03 & 0.41 & 12.3 \\
\hline
\end{tabular}




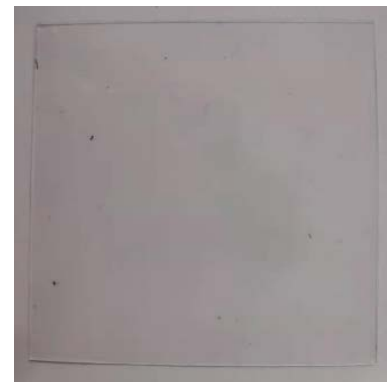

(a) Before spraying

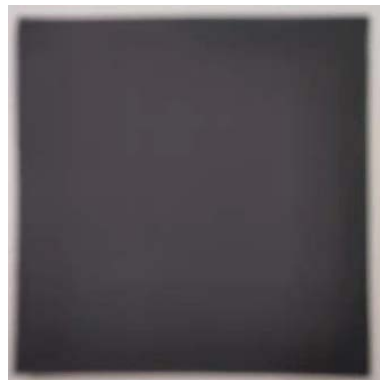

(b) After spraying

Figure 1. XLPE Diagram before and after Spraying Semiconductive Layer

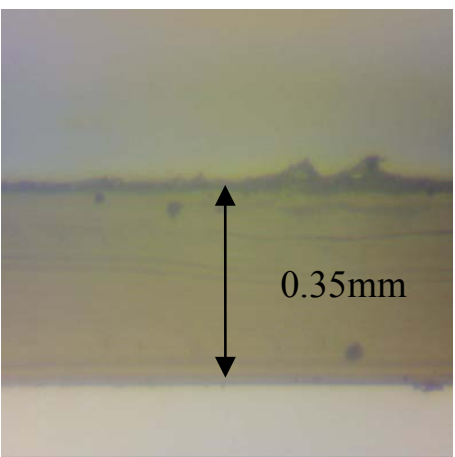

(a) Thickness of XLPE
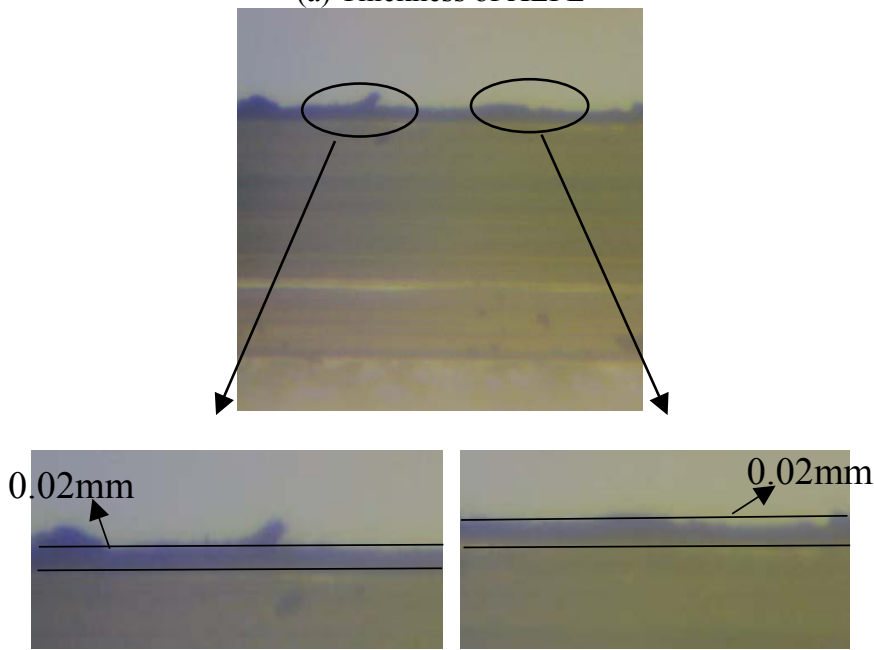

(b) Thickness of Semiconductive Layer

Figure 2. Measurement schematic diagram

\subsection{Test System}

The space charge measurement system based on electro-acoustic pulse (PEA) method is shown in Fig. 3. The DC voltage output is controlled by using LabVIEW software program, so that the linear boost of XLPE sample can be achieved. The structure of the test device is shown in Fig. 4. The space charge distribution characteristics of the sample under different DC electric fields are measured. Among them, copper $(\mathrm{Cu})$ electrode is used as the upper 
electrode of PEA measurement system, aluminum (Al) electrode as the lower electrode and silicone oil as the acoustic coupling agent.

PEA space charge measurement system mainly includes:

- High voltage DC power supply, voltage range 0-30 kV

- ns pulse source, pulse width $10 \mathrm{~ns}$, amplitude $600 \mathrm{~V}$, resolution 30 micron

- The upper electrode is copper, and the lower electrode is made of aluminium for better transmission of acoustic signals.

- Oscilloscope, Like WaveRunner 4-channel oscilloscope

- The computer communicates with the oscilloscope to save the acquisition signal

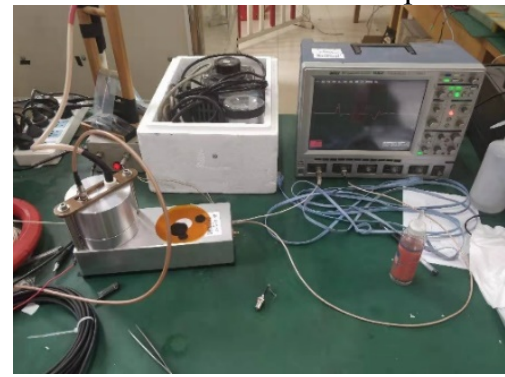

Figure 3. Space Charge Measurement System Based on Electroacoustic Pulse (PEA) Meth

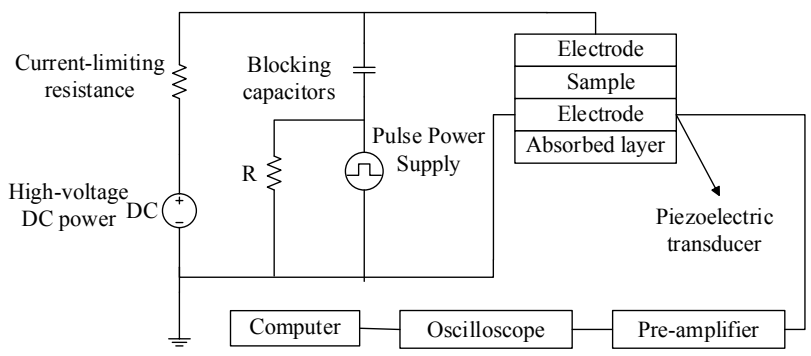

Figure 4. Structural Chart of Test Device

\section{Testing Principle and Method}

\subsection{Testing Principle}

The basic principle of space charge measurement by electroacoustic pulse method is to apply a high voltage pulse with very narrow pulse width on the sample. Under the action of this pulse, the space charge in the sample will generate corresponding pressure wave pulse. The pressure profile of the pressure wave pulse is related to the volume density distribution of space charge in the sample and is received by piezoelectric sensor. By measuring the pressure wave pulse, the distribution of space charge in the corresponding sample can be obtained.

\subsection{Testing method}

The purpose of this experiment is to study the effect of the thickness of semiconducting layer on space charge accumulation in XLPE. For this reason, the following test procedures were carried out for 10 and $220 \mathrm{kV}$ samples with different thickness.

The XLPE samples were rapidly pressurized to $30 \mathrm{kV} / \mathrm{mm}$ by spraying semi-conductive 
paint on uncoated slices and 2 or 3 layers. After waiting for 10 seconds, the field strength was maintained for 30 minutes at this time point, and then the pressure was rapidly lowered to $0 \mathrm{kV}$ and continued for 90 minutes. Then, new samples were selected to repeat the above process.

The curves of space charge density varying with sample thickness at $10 \mathrm{~s}, 300 \mathrm{~s}, 1200 \mathrm{~s}$ and 1800 s were selected for analysis and comparison.

\section{Results and Discussions}

\subsection{Space Charge Distribution of 10kV XLPE under Different Semiconductive Layer Thicknesses}

The test results are shown in Fig. 5-7. The peak value on the left side is the anode interface, the peak value on the right side is the cathode interface, the vertical axis is the space charge density, and the transverse axis is the sample thickness.

From the results, it can be concluded that during the process of high voltage direct current compression, there is a positive charge accumulation near the positive peak (positive electrode), and the space charge inside the sample is almost zero. Compared with uncoated slices, the negative charge accumulation phenomenon of coated slices is more obvious near the negative peak. Near the positive and negative electrodes, the polarity of charge accumulation is consistent with that of the positive and negative electrodes.

\subsection{Space Charge Distribution of $220 \mathrm{kV}$ XLPE under Different Semiconductive Layer Thicknesses}

The test results are shown in Fig. 8-10, and the parameters in the figure are the same.

From the test results, it can be concluded that the $220 \mathrm{kV}$ sample is similar to the $10 \mathrm{kV}$ sample in that it accumulates negative charges near the negative peak, and the sample with coating accumulates more and more in a wider range; all the heteropolar charges near the positive pole of the $220 \mathrm{kV}$ sample are accumulated, and the charges near the positive pole of the sample with coating are more obvious; The positive charge accumulated and increased with the increase of coating thickness. The thicker the coating, the more the peak charge accumulated in 30 minutes.

In summary, for 10 and $220 \mathrm{kV}$ samples, the charge accumulation at the positive and negative peaks (anode and cathode interface) of semi-conductive coatings is significantly higher than that without coatings, and the thicker the semi-conductive layer is, the more the charge accumulation is. However, for the accumulation of positive charges near the interface of $10 \mathrm{kV}$ anode and negative charges near $220 \mathrm{kV}$ anode, further research and demonstration are needed.

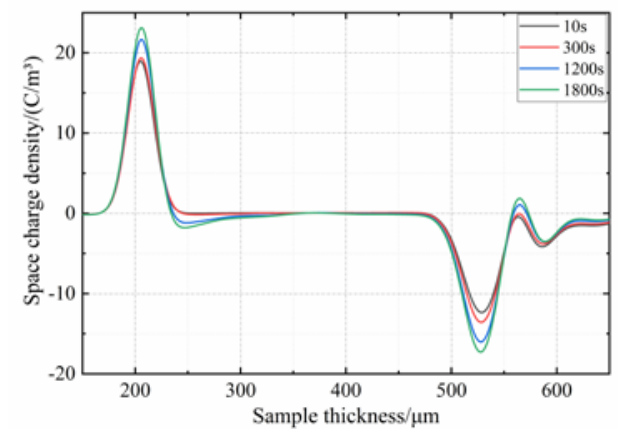


Figure 5. Change of Space Charge Density with Sample Thickness in 10kV Coated-free XLPE

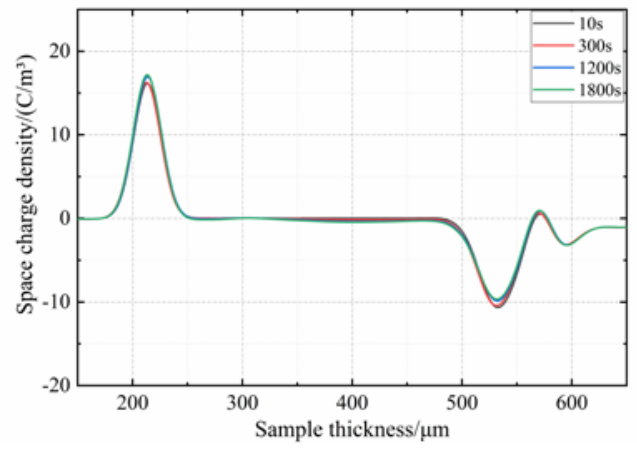

Figure 6. Change of Space Charge Density with Sample Thickness in 10kV 2-Layer Coating XLPE

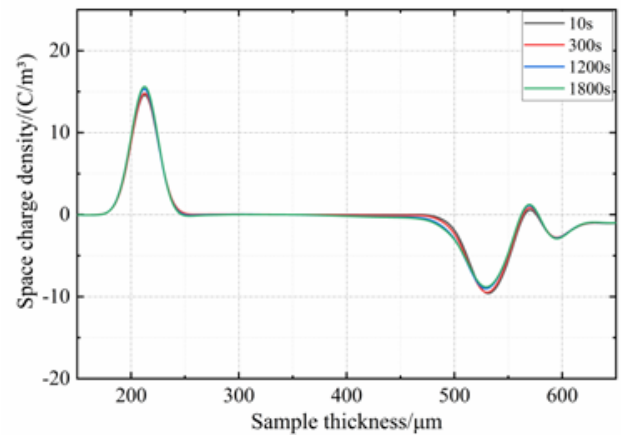

Figure 7. Change of Space Charge Density with Sample Thickness in 10kV 3-Layer Coating XLPE

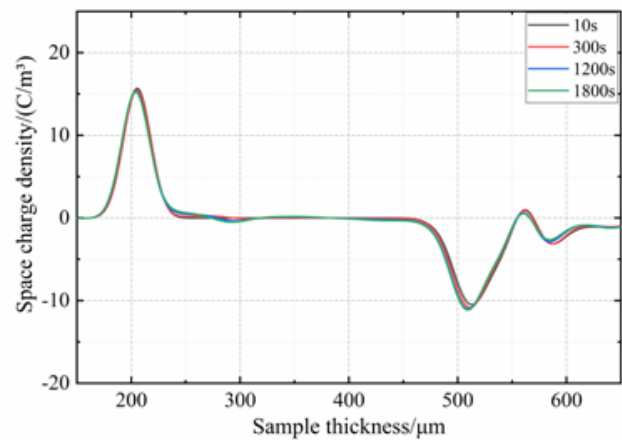

Figure 8. Change of Space Charge Density with Sample Thickness in 220kV Coated-free XLPE

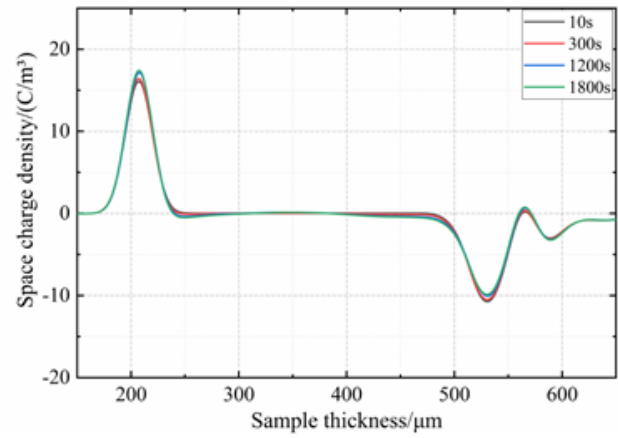


Figure 9. Change of Space Charge Density with Sample Thickness in 220kV 2-Layer Coating XLPE

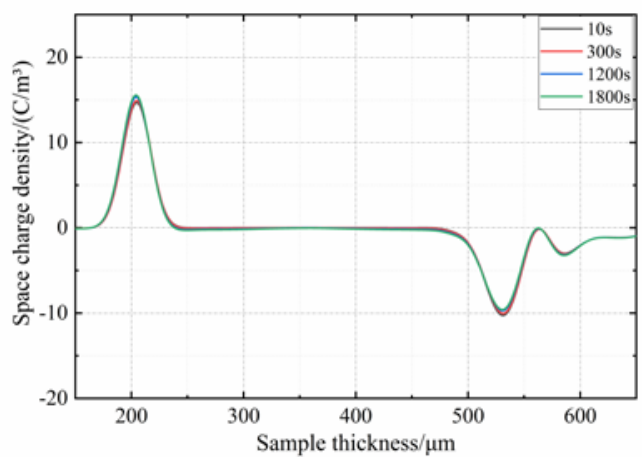

Figure 10. Change of Space Charge Density with Sample Thickness in 220kV 3-Layer Coating XLPE

\section{Conclusions}

Through the research of the thesis, we have obtained the following main conclusions. During the maintaining pressure stage, the semi-conductive coating can accumulate space charge near the anode and cathode. The thicker the semiconducting layer is, the more obvious the accumulation of space charge is. The longer the pressure is maintained, the more space charge accumulates.

\section{References}

1. ZHONG Lisheng, REN Haiyang, CAO Liang, et al.Development of high voltage direct current extruded cables[J]. High Voltage Engineering, 2017, 43(11): 3473-3489.

2. GULSKI E, SMIT J J, SEITZ P N, et al. PD measurements on-site using oscillating wave test system[C]//IEEE International Symposium on Electrical Insulation. Canada: [s.n.], 1998: 420-423

3. ZHAO Jiankang, ZHAO Peng, CHEN Zhengzheng, et al. Review on progress of HVDC cables insulation materials[J]. High Voltage Engineering, 2017, 43(11): 34903503 .

4. LIU Jun, WU Guangning, ZHOU Kai, et al. Space charge measuring device based on PEA method[J]. High Voltage Engineering, 2009, 35(3): 607-612..

5. WANG Wei, SUN Hui, LI Fuping, et al. Space charge measurement and characteristics in the actual cable[J]. Transactions of China Electrotechnical Society, 2015, 30(1): 255260.

6. ZHONG Qiongxia, LAN Li, WU Jiandong, et al. The influence of cross-linked byproducts on space charge behaviour in XLPE[J]. Proceedings of the CSEE, 2015, 35(11): 2903-2910.

7. CHEN Zhengzheng, ZHAO Jiankang, MENG Shaoxin, et al. Space charge characteristics of HVDC XLPE cables in the load cycle test for 30 days [J]. High Voltage Engineering, 2016, 42(8): 2416-2425.

8. OUYANG Benhong, ZHAO Jiankang, CHEN Zhengzheng, et al. Relationship between space charge and physicochemical properties of AC XLPE cables[J]. Insulation 
Materials, 2012, 45(3): 47-50.

9. MURATA K, TANAKA Y, TAKADA T. Space charge formation in XLPE with low frequency $\mathrm{AC}$ voltage [C]// IEEE International Symposium on Electrical Insulating Materials. [S.1.]: IEEE, 1995: 17-20.

10. VISSOUVANADIN B, ROY S L, TEYSSÈDRE G, et al. Impact of concentration gradient of polarizable species on the electric field distribution in polymeric insulating material for HVDC cable[J]. IEEE Transactions on Dielectrics and Electrical Insulation, 2011, 18(3): 833-839.

11. TANAKA T. Dielectric properties of XLPE/SiO2 nano-composites based on CIGRE WG D1.24 Cooperative test results[J]. IEEE Transactions on Dielectrics and Electrical Insulation, 2011, 18(5): 1484-1517.

12. LI Y, KAWAI J, EBINUMA Y, et al. Space charge behavior under AC voltage in water-treed PE observed by the PEA method[J]. IEEE Transactions on Dielectrics and Electrical Insulation, 1997, 4(1): 52-57.. 